LINGUA, Vol. 15, No. 2, September 2018

p ISSN: 1979 9411; e ISSN: 2442 238X

Http://lingua.pusatbahasa.or.id; Email:presslingua@gmail.com

Center of Language and Culture Studies, Surakarta, Indonesia

Irwansyah, Arifudin \& Yusran, Kamaludin. 2018. Nilai Nilai Mantra Bercocok Tanam di Desa Campa Kecamatan Madapangga Kabupaten Bima.

Lingua (2018), 15(2):175 186. DOI: 10.30957/lingua.v15i2.492.

\title{
NILAI-NILAI MANTRA BERCOCOK TANAM DI DESA CAMPA KECAMATAN MADAPANGGA KABUPATEN BIMA
}

\author{
Irwansyah, Arifudin \& Kamaludin Yusran
}

Magister Pendidikan Bahasa Indonesia Universita Mataram

Jl. Majapahit No. 62, Gomong, Selaparang, Dasan Agung Baru, Selaparang, Kota Mataram, Nusa Tenggara Barat 83115

Corresponding Email: danuaja36@gmail.com

\begin{abstract}
This study explores the nature of mantra for the rice breeding in Campa Village, Madapangga District the regent of Bima. As the indigenous people belive on the aesthetical and spiritual of the mantra, this study tries to explore how society especially the villagers who mostly are farmers perceive values in the mantra. This syudy used ethnograpy and approached the data analysis using qualitative methods. Five informants having authority in the mantra were interviewed and harvesting rice was used as research setting. Observation, interview and document analysis were the sources of data in this research. This study reveals that aqidah (God trust) values are the most values people believe as the total renderness to Allah as the absolute truth. Reying on Allah wish, people involve activities of plantation rice for success. The second value is syariah (law) from where people rule and apply their social and daily life activities. The third value is moral (akhlak) to maintain their surrounding in peace, safe and sustainable.
\end{abstract}

Keywords: mantra, Islamic values, trust, faith, moral.

DOI: 10.30957/lingua.v15i2.492.

\section{PENDAHULUAN}

Ketika masyarakat sudah mulai meninggalkan tradisi, maka tidak dimungkiri bahwa sebenarnya masyarakat sudah meninggalkan nilai-nilai luhur yang dianutnya secara turun temurun. Dalam kegiatan bertani misalnya, adanya penuturan mantra merupakan suatu upaya memohon perlindungan kepada yang kuasa di luar kekuasaan manusia. Hal tersebut menunjukkan adanya kesadaran bahwa manusia memiliki keterbatasan dan memiliki kemampuan untuk berusaha, salah satunya adalah berdoa kepada yang menguasai kehidupan. Oleh sebab itu, perlu kiranya ada penelitian mengenai mantra, bertujuan untuk menggali nilai-nilai kearifan dengan harapan dapat digunakan dalam kehidupan masyarakat dan tetap dipertahankan di era modern sekarang ini.

Menurut Richard (dalam Suyasa, 2004:2) bahwa mantra sebagai ekspresi manusia yang diyakini mampu mengubah suatu kondisi karena dapat memunculkan kekuatan 
LINGUA, Vol. 15, No. 2, September 2018

p ISSN: 1979 9411; e ISSN: 2442 238X

Http://lingua.pusatbahasa.or.id; Email:presslingua@gmail.com

Center of Language and Culture Studies, Surakarta, Indonesia

Irwansyah, Arifudin \& Yusran, Kamaludin. 2018. Nilai Nilai Mantra Bercocok Tanam di Desa Campa Kecamatan Madapangga Kabupaten Bima.

Lingua (2018), 15(2):175 186. DOI: 10.30957/lingua.v15i2.492.

gaib, estetik, dan penuh mistis, historis, mantra disamping memiliki konsep acuan yang lain juga pijakannya bersumber pada agama. Mantra dalam perkembangannya membentuk acuan dan dari acuan itu muncul bentuk-bentuk sastra yang bersifat psikologis, mistis, simbolis, dan impresif.Mantra memiliki nilai kebersamaan dalam hal yang positif dengan cara membacakan mantra pengasih terhadap sesama dalam hal ini mantra akan menciptakan satu sistem kebersamaan keinginan antara yang membacakan mantra dengan orang lain. Disisi lain mantra juga memiliki nilai yang buruk (negatif) ketika pembaca menggunakan mantra sihir terhadap seseorang ataupun sekelompok orang karena ini akan meciptakan perpecahan dan permusuhan antar sesama (Jalil dan Elmustian, 2001:33).

Penelitian mengenai mantra pertanian pernah dilakukan Rakem dalam skripsinya yang berjudul Mantra Bercocok Tanam Padi Sawah di desa Leuweunggede pada tahun 2008. Kajian tersebut memaparkan beberapa jenis mantra yang digunakan dalam pertanian, yaitu mantra membakar kemenyan ketika akan membajak sawah, mantra menebar benih, dan mantra ketika padi sudah mulai terlihat bulirnya yang hijau dan berisi, memotong padi dan menyimpan ke lumbung.

Dalam kajiannya, Rakem memaparkan bahwa struktur teks mantra "Bercocok Tanam Padi Sawah" memiliki klausa yang unsur-unsurnya tidak selalu berurutan. Dari segi bunyi, majas dan tema, teks mantra banyak mengandung pengulangan kata yang dimaksudkan untuk mempertegas makna. Selanjutnya konteks penuturan menjadi dua tahapan, pertama oleh dukun yang menuturkan mantra sambil menerangkan mantra kepada pengamal, kemudian kedua ialah penuturan oleh pengamal diiringi laku mistik untuk mencapai tujuannya. Proses pewarisan bersifat vertikal, yaitu dari guru kepada muridnya yang dikenal dengan istilah izajah. Dalam proses penciptaannya dilakukan secara terstruktur; dan kempat, fungsi dari mantra bercocok tanam padi sawah adalah sebagai sistem proyeksi, yaitu sebagai gambaran angan-angan masyarakat pemilik mantra bercocok tanam padi sawah tersebut.

Desa-desa di wilayah kota dan kabupatenBima merupakan desa yang kental pada budaya dan diwariskan secara turun-temurun. Budaya yang diwariskan ini hampir ada dalam setiap aspek baik pada aspek pertanian, pernikahan bahkan dalam kesehariannya masyarakat di wilayah kota dan kabupaten Bima selalu berbudaya.

Desa Campa merupakan wilayah yang ada di kecamatan Madapangga kabupaten Bima provinsi Nusa Tenggara Barat. Desa Campa merupakan wilayah yang letak geografisnya berada di wilayah cekungan dan dikelilingi oleh bukit (gunung). Masyarakat di desa ini merupakan masyarakat yang juga kental terhadap budaya yang diwariskan secara turun-temurun seperti budaya-budaya yang dipraktekan di desadesalainya di kabupaten Bima, seperti budaya kapatu (pantun) Mbojo, mantra yang biasa mereka bacakan pada saat menyembuhkan orang sakit, mulai bercocok tanam, mulai mendirikan rumah, dan lain-lain (Observasi 27 Maret 2015).

Desa Campa juga merupakan desa yang sudah terkontaminasi oleh era modern yang mulai menggantikan dan mengikis budaya awal masyarakat sehingga berdasarkan wawancara yang dilakukan kepada tokoh masyarakat setempat bahwa mantra masih ada 
LINGUA, Vol. 15, No. 2, September 2018

p ISSN: 1979 9411; e ISSN: 2442 238X

Http://lingua.pusatbahasa.or.id; Email:presslingua@gmail.com

Center of Language and Culture Studies, Surakarta, Indonesia

Irwansyah, Arifudin \& Yusran, Kamaludin. 2018. Nilai Nilai Mantra Bercocok Tanam di Desa Campa Kecamatan Madapangga Kabupaten Bima.

Lingua (2018), 15(2):175 186. DOI: 10.30957/lingua.v15i2.492.

dalam tradisi masyarakat Campa saat mulai bercocok tanam, tetapi yang mengkuatirkan adalah kurangnya perhatian untuk mempertahankan budaya ini dari generasi muda.

Berdasarkan uraian latarbelakang masalah di atas peneliti tertarik untuk melakukan penelitian tentang "Nilai-Nilai Mantra Bercocok Tanam pada Masyarakat Desa Campa Kecamatan Madapangga Kabupaten Bima”. Untuk itu, rumusan masalah dalam penelitian ini ialah bagaimanakah nilai-nilai mantra bercocok tanam masyarakat desa Campa kecamatan Madapangga kabupaten Bima?

\section{LANDASAN TEORI}

Kata folklor berasal dari bahasa Inggris, yaitu folklore. Dari dua kata dasar, yaitu folk dan lore. Menurut Alan Dundes (dalam Danandjaja 2002:1-2), folk adalah sekelompok orang yang memiliki ciri-ciri pengenal fisik, sosial, dan kebudayaan, sedangkan lore adalah tradisi folk, yaitu sebagian kebudayaannya, yang diwariskan secara turun-temurun secara lisan atau melalui suatu contoh yang disertai dengan gerak isyarat atau alat pembantu pengingat (mnemonic device).

Jadi folklor dilihat dari bentuknya terbagi menjadi tiga kelompok besar yakni folklor lisan merupakan kelompok folklor yang murni lisan, kemudian folklor sebagian lisan merupakan folklor yang sebagianya lisan dan sebagian lainya ada unsur non lisan seperti benda dan gerakan tubuh, kemudan folklor bukan lisan merupakan folklor yang tidak ada usur lisanya. Endraswara (2009:29-30) menggolongkan folklor kedalam tiga golongan yaitu: (1) Folklor lisan yaitu folklor yang banyak diteliti orang. Bentuk folklor lisan dari yang sederhana yaitu ujaran rakyat yang bisa dirinci dalam bentuk julukan, dialek, ungkapan, dan kalimat tradisional, pertanyaan rakyat, mite, legenda, nyanyian rakyat, dan sebagainya; (2) folklor adat dan kebiasaan yang mencakup jenis folklor lisan dan non lisan misalnya kepercayaan rakyat, adat istiadat, pesta, permainan rakyat; (3) folklor material mencakup seni karia, arsitektur, busana, makanan, dan lain-lain.

\subsection{Pengertian Mantra}

Mantra sebagaimana dikemukakan oleh Poerwadarminta (dalam Delvayanti, 2012:3) adalah: (1) Perkataan atau ucapan yang mendatangkan daya gaib (misal dapat menyembuhkan, mendatangkan celaka, dan sebagainya), dan (2) Susunan kata berunsur puisi (seperti rima, irama) yang dianggap mengandung kekuatan gaib, biasanya diucapkan oleh dukun atau pawang untuk menandingi kekuatan gaib yang lain. Jadi mantra merupakan susunan perkataan atau ucapan yang berunsur puisi yang dianggap mengandung kekuatan gaib, yang diucapkan oleh dukun atau pawang untuk memenuhi kebutuhan pengguna.

Harun (dalam Delvayanti, 2012:11) menjelaskan ciri-ciri mantra sebagai berikut: (1) Mantra merupakan bentuk dari puisi, (2) Isi dan konsepnya memiliki hubungan yang rapat dengan sistem kepercayaan yang dianut oleh masyarakat, (3) Diciptakan dan diabadikan dalam satu perlakuan dengan fungsi tertentu dibacakan oleh pawing (Bima sando), dan (4) Kepercayaan, konsep, teks, serta amalan dan perlakuan dipraktekan untuk tujuan perseorangan maupun masyarakat dengan tujuan baik maupun tujuan jahat. 
LINGUA, Vol. 15, No. 2, September 2018

p ISSN: 1979 9411; e ISSN: 2442 238X

Http://lingua.pusatbahasa.or.id; Email:presslingua@gmail.com

Center of Language and Culture Studies, Surakarta, Indonesia

Irwansyah, Arifudin \& Yusran, Kamaludin. 2018. Nilai Nilai Mantra Bercocok Tanam

di Desa Campa Kecamatan Madapangga Kabupaten Bima.

Lingua (2018), 15(2):175 186. DOI: 10.30957/lingua.v15i2.492.

\subsection{Nilai Religius}

Menurut Mangunwijaya (dalam Trenggalek, 2013:01) istilah religi menunjukkan pada aspek religi yang telah dihayati oleh individu dalam hatinya. Ancok dan Suroso (dalam Trenggalek, 2013:02) menyatakan bahwa religi merupakan perilaku terhadap agama yang berupa penghayatan terhadap nilai-nilai agama yang dapat ditandai tidak hanya melalui ketaatan dalam menjalankan ibadah ritual tetapi juga dengan adanya keyakinan, pengamalan, dan pengetahuan menganai agama yang dianutnya.

Berdasarkan paparan tersebut, dapat ditarik sebuah simpulan bahwa nilai religius merupakan suatu konsep kepercayaan yang disadari seseorang sebagai bentuk internalisasi agama dalam diri individu.

\subsection{Nilai Akhlak}

Akhlak berarti perangai, adat istiadat, tabi'at atau sistem perilaku yang dibuat. Akhlak menurut istilah adalah sikap seseorang yang dimanifestasikan ke dalam perbuatan dan tingkah laku.Aklak menurut istilah ialah sikap seorang yang dimanifestasikan ke dalam perkataan perbuatan dan tingkah laku (Nurlela, 1999:91).

Bercocok Tanam

Bercocok tanam padi/budidaya padi adalah kegiatan yang betujuan mendapatkan hasil yang setinggi-tinginya dengan kualitas sebaik mungkin, untuk mendapatkan hasil yang sesuai dengan harapan maka, tanaman yang akan ditanam harus sehat dan subur. Lahan becocok tanam diolah untuk meningkatkan kesuburan tanah sebagai media tumbuh tanaman padi. Tahapan pengolahan lahan, pada lahan basah/sawah (Rakem, 2008:12-15).

a) Pengolahan Lahan dan penanaman. Masa pengolah lahan akan mencakup masa masyarakat petani mulai membuka lahan, biasa masa membuka lahan ini di daerah daerah pedesaan akan dimulai pada awal musim hujan. Masa pengolahan lahan dan penanaman akan mencakup masa mulai membajak sawah, garu, kemudian memilih benih, sampai pada masa penanaman.

b) Perawatan. Padi adalah jenis tanaman yang memerlukan perawatan untuk pertumbuhannya. Perawatan dapat berupa pemupukan dan penanggulangan hama; pemupukan pada tanaman padi dapat menggunakan pupuk urea, pupuk $\mathrm{Kcl}$, dan poshpat. Adapun tata cara pemupukan yang ideal untuk tanaman padi adalah dengan memperhatikan kondisi tanah dan tanaman itu sendiri. Kondisi tanah yang harus diperhatikan adalah keasaman tanah, sementara dari tanaman adalah dengan melihat seberapa besar pertumbuhan tanaman; dengan kata lain pertumbuhan harus sesuai dengan kriteria yang ada. Sementara itu untuk penanggulangan hama penyakit dapat digunakan berbagai macam obat-obatan misal akodan, dencis dll.

Berdasarkan rujukan di atas masa bercocok tanam yang peneliti teliti ialah mulai masa pengolahan lahan dan penanaman sampai masa perawatan. Tujuan pembatasan ini agar memungkinkan peneliti memperoleh data yang valid mengenai mantra bercocok 
LINGUA, Vol. 15, No. 2, September 2018

p ISSN: 1979 9411; e ISSN: 2442 238X

Http://lingua.pusatbahasa.or.id; Email:presslingua@gmail.com

Center of Language and Culture Studies, Surakarta, Indonesia

Irwansyah, Arifudin \& Yusran, Kamaludin. 2018. Nilai Nilai Mantra Bercocok Tanam di Desa Campa Kecamatan Madapangga Kabupaten Bima.

Lingua (2018), 15(2):175 186. DOI: 10.30957/lingua.v15i2.492.

tanam, karena masa bercocok tanam masyarakat desa Campa pada musim tanam 20152016 baru masuk pada masa pengolahan lahan dan penanaman sampai masa perawatan sedangkan masa panen belum dilalui oleh masyarakat desa Campa

\section{METODE}

Jenis penelitian adalah penelitian etnografi dengan pendekatan penelitian kualitatif. Penelitian etnografi adalah penelitian yang membahas dan mengkaji teks-teks mantra dalam masyarakat. Penelitian ini bertujuan untuk melakukan studi mendalam terhadap masyarakat desa Campa kecamatan Madapangga kabupaten Bima saat mengucapkan mantra ketika melaksanakan aktifitas pertanian (bercocok tanam). Adapun tehnik pengumpulan data yaitu menggunakan metode wawancara dan dokumentasi. Teknik analisis data yang digunakan dalam penelitian ini ialah analisis model alur interaktif sebagaimana dikemukakan oleh Miles dan Huberman (dalam Sugiyono, 2012:334) yang terdiri atas tiga tahap yakni reduksi data, penyajian data, dan verifikasi data.

\section{HASIL DAN BAHASAN}

\subsection{Data Aqidah}

1. Tuturan:

"Audzubillah himinasyaitonirrajim

Bismillahirrahmanirrahim

Bismillahi amantu billah, tawakkaltu 'alAllahi la haula wala quwwata illa billahi-'aliyyil-'azim Alloohumma Innaa Nas-Aluka Salaamatan Fid Diini Wa 'Aafiyatan Fil Jasadi Wa Ziyaadatan Fil 'Ilmi Wa Barokatan Fir Rizqi Wa Taubatan Qoblal Mauti Wa Rohmatan 'Indal Mauti Wa Maghfirotan Ba'dal MautiBarekala Illa Ha Ilallah Bareka Muhammadarrasulullah (W/HAR/AQ/10/11/15).

Data di atas diperoleh keterangan bahwa nilai religius yang terkandung pada mantra bercocok tanam masa pengolahan lahan dan penanaman ialah nilai aqidah. Hal ini berdasarkan arti mantra sebagai berikut; " Aku berlindung kepada allah dari godaan syetan yang terkutuk. Dengan menyebut nama allah yang maha pengasih lagi maha penyayang. Dengan nama Allah aku beriman kepada Allah, aku berserah diri kepada Allah tiada daya dan kekuatan melainkan atas pertolongan Allah yang maha tinggi lagi maha agung. Ya Allah kami memohon kepadaMu keselamatan dalam agama, dan kesejahteraan/kesegaran pada tubuh dan penambahan ilmu, dan keberkahan rizqi, serta taubat sebelum mati dan rahmat di waktu mati, dan keampunan sesudah mati.

Data tersebut mengandung nilai akidah karena mengandung unsur kepercayaan dan kayakinan masyarakat secara totalitas kepada Allah SWT sebagai pemberi perlindungan, pemberi rejeki, pemberi keselamatan. 


\section{Tuturan:}

"...Bismillahirrahmanirrahim

Allahumma salli ala Muhammad

Allahumma salli ala sayidina Muhammad

Allahumma salli ala sayidina Muhammadin wa ala alisayidinaa Muhammad BarekalalllaHallallah Bareka Muhammadarrasulullah..."(W/MA/AQ/10/11/15).

Data di atas memiliki arti sebagai berikut; "Dengan menyebut nama Allah yang maha pengasih lagi maha penyanyang. Ya tuhan kami, syalawatkanlah ke atas nabi Muhammaddan. Ya tuhan kami, syalawatkanlah ke atas pemimpin kami nabi Muhammaddan. Ya tuhan kami, syalawatkanlah ke atas pemimpin kami nabi Muhammad dan keatas keluarganya. Berdasarkan arti mantra tersebut, maka mantra tersebut mengandung nilai aqidah karena mengandung unsur rukun iman kepada Allah dan rukun iman kepada para nabi.

\section{Tuturan:}

"...Bismillahirrahmanirrahiim.

Asyhadu an laa ilaaha illAllah

Wa asyhadu anna uhammadarrasulullah.

BarekalallaHallallah Bareka Muhammadarrasulullah..."(W/HAW/AQ/13/11/15)

Pada data di atas memiliki arti sebagai berikut; Dengan menyebut nama Allah yang maha pengasih lagi maha penyayang. Aku bersaksi tiada tuhan selain Allah. Dan aku bersaksi bahwa Muhammad utusan Allah. Nilai aqidah pada mantra tersebut karena persaksian manusia bahwa tidak ada tuhan selain Allah dan nabi Muhammad adalah utusan Allah.

Persaksian manusia bahwa tidak ada tuhan selain Allah dan nabi Muhammad adalah utusan Allah merupakan dasar dari aqidah islam seorang muslim, hal ini karena persaksian tersebut mengandung makna mempercayai dan meyakini bahwa hanya Allah SWT tuhan penguasa alam semesta serta mempercayai dan meyakini bahwa nabi Muhammad merupakan utusan Allah di atas muka Bumi sebagai pemimpin ummat dan nabi akhir jaman.

Berdasarkan data maka peneliti menyimpulkan data tersebut mengandung nilai religius aqidah. Aqidah menurut Menurut Hidayat, dkk (dalam Santi, dkk. 2013:446) berasal dari kata $a l-a q d u$ yang berarti ikatan, at-tausiqu yang berarti kepercayaan atau keyakinan yang kuat, al-ihkamu artinya mengukuhkan atau menetapkan, dan ar-rabtu biquwwah yang berarti mengingkatkan dengan kuat. Menurut istilah, aqidah Islam adalah ajaran tentang kepercayaan yang teguh terhadap ajaran Islam yang yang meliputi kemahaesaan Allah Swt dan segala ajaran-Nya.

Sedangkan menurut Muslim (dalam Nurlela, 1999:34) aqidah berasal dari kata aqadha-ya-qidu-aqdan, yang bearti mengikat, mempercayai dan meyakini. Kata ini juga sering diungkapkan dalam ungkapan-ungkapan seperti akad nikah atau akad jual-beli. Dengan demikian aqidah bisa diartikan sebagai ikatan antara manusia dengan 
LINGUA, Vol. 15, No. 2, September 2018

p ISSN: 1979 9411; e ISSN: 2442 238X

Http://lingua.pusatbahasa.or.id; Email:presslingua@gmail.com

Center of Language and Culture Studies, Surakarta, Indonesia

Irwansyah, Arifudin \& Yusran, Kamaludin. 2018. Nilai Nilai Mantra Bercocok Tanam di Desa Campa Kecamatan Madapangga Kabupaten Bima.

Lingua (2018), 15(2):175 186. DOI: 10.30957/lingua.v15i2.492.

Tuhannya. Kemudian menurut Al-Atsari (2005:28) aqidah adalah hal-hal yang wajib dibenarkan oleh hati dan jiwa merasa tentram kepadanya, sehingga menjadi keyakinan kukuh yang tidak tercampur oleh keraguan.

\subsection{Data Syariah}

Berdasarkan klasifikasi diatas data syariah diperoleh melalui keterangan narasumber sebagai berikut:

1. Tuturan:

"...Bismillahirrahmanirrahiim. Asyhadu an laa ilaaha ill Allah Wa asyhadu anna
$\begin{aligned} & \text { Muhammadarrasulullah. } \\ & \text { Bareka }\end{aligned}$ lalla
$\begin{aligned} & \text { Muhammadarrasulullah..."(W/HAW/SY/13/11/15) } \\ & \text { Bareka }\end{aligned}$

Pada data di atasmemiliki arti sebagai berikut; "aku bersaksi bahwa tidak ada tuhan selain Allah dan aku bersaksi bahwa Muhammad adalah utusan Allah". Data tersebut mengandung nilai syariah karena merupakan kalimat syahadat, kalimat syahadat merupakan rukun islam yang pertama menjadi ruang lingkup kajian nilai syariah.

2. Tuturan:

"...bismillahirrahmanirrahiim

Rumae mada doho di adamu manemba ndai ita ta ruma di ade babukai kanggihi lamada dohoke mbei japu mori ra woko di ruuba kanggihi lamada doho loa kaira wara di ngaha ra mori ra woko kai mada doho loakara tenggo sambea ra nemba di ndai ita ta rumae..." (W/HMHI/SY/13/11/15)

Pada data di atas memiliki arti sebagai berikut; "ya Allah kami sebagai hambamu menyembah engkau di saat kami memulai penanaman. Hidupkanlah dan perilaharalah tanaman kami supaya kami memiliki bekal untuk hidup. Sehingga kami kuat untuk selalu beribadah kepadamu". Arti mantra diatas mengandung nilai syariah karena adanya keinginan yang kuat dari masyarakat untuk selalu menyembah dan beribadah kepada tuhan.

3. Tuturan:

"...bismillahirrahmanirrahiim

Ake madama babu kanggihi rumae, mbeijabu rejeki di ruuma mada adamu di ade kanggihi ra ngguda ra congge mada ake rumae, di loakai mori mada doho la adamu, di loakai beribadah ta ita rumae, nawarakura harta lamada di beribadah kai ta ita di sadeka kai lamada rumae loa kaira mada ndadi ada ma toa tai rumae barekala illaha illallah bareka muhammadarrasulullah..."(W/T/SY/21/11/15)

Pada data di atas memiliki arti sebagai berikut; "dengan menyebut nama Allah yang maha pengasih lagi maha penyayang. Ya Allah inilah hamba yang memulai 
LINGUA, Vol. 15, No. 2, September 2018

p ISSN: 1979 9411; e ISSN: 2442 238X

Http://lingua.pusatbahasa.or.id; Email:presslingua@gmail.com

Center of Language and Culture Studies, Surakarta, Indonesia

Irwansyah, Arifudin \& Yusran, Kamaludin. 2018. Nilai Nilai Mantra Bercocok Tanam di Desa Campa Kecamatan Madapangga Kabupaten Bima.

Lingua (2018), 15(2):175 186. DOI: 10.30957/lingua.v15i2.492.

menanam di sawah dan ladang kami, berilah rezeki buat hamba yang sebagai petani di sawah dan di ladang kami, sehingga kami sebagai hambamu tetap bertahan hidup, untuk terus beribadah dan menyembah engkau, sehingga kami memiliki harta untuk beribadah kepadamu, untuk bersedekah kepada sesama, sehingga kami tergolong hamba-hambamu yang taat. Berkatilah ya Allah". Mantra tersebut mengandung unsur nilai syariah karena memuat nilai ibadah untuk menyembah tuhan serta bersedekah menjalankan syariat Islam.

Syariah adalah ketentuan-ketentuan Allah Swt yang mengatur tentang suatu perbuatan yang akan dilaksanakan atau tidak dilaksanakan oleh seseorang serta tujuan dari perbuatan itu, baik dalam bentuk ibadah khusus maupun ibadah umum (Nasrul, dkk. 2010:163). Menurut Nurlela (1999:61) Nilai Syariah adalah ketentuan Allah yang mengatur hubungan manusia dengan Allah secara vertikal, mengatur hubungan antara manusia dengan sesama manusia dan makhluk lainnya secara horizontal. Ketentuan-ketentuan Allah itu mengatur tentang ibadah khususnya (ibadah mahdah) dan ibadah umum (ibadah ghairu magdah).

Pendapat lain dikemukakan oleh Kamil (2007:24). Syariah merupakan jalan yang ditetapkan Allah SWT dan manusia harus mengarahkan hidupnya untuk merealisasikan kehendak tuhan. Kajian syariah tertumpu pada masalah aturan Allah dan Rasul-Nya atau masalah hukum. Aturan atau hukum ini mengatur manusia dalam berhubungan dengan Tuhannya (hablun minallah) dan dalam berhubungan dengan sesamanya (hablun minannas). Kedua hubungan manusia inilah yang merupakan ruang lingkup dari syariah Islam. Hubungan yang pertama itu kemudian disebut dengan ibadah, dan hubungan yang kedua disebut muamalah.Ibadah mengatur bagaimana manusia bisa berhubungan dengan Allah. Dalam arti yang khusus (ibadah mahdlah), ibadah terwujud dalam rukun Islam yang lima, yaitu mengucapkan dua kalimah syahadah (persaksian), mendirikan shalat, menunaikan zakat, berpuasa di bulan Ramadhan, dan pergi haji bagi yang mampu. Sedang muamalah bisa dilakukan dalam berbagai bentuk aktivitas manusia dalam berhubungan dengan sesamanya. Bentuk-bentuk hubungan itu bisa berupa hubungan perkawinan (munakahat), pembagian warisan (mawaris), ekonomi (muamalah), pidana (jinayah), politik (khilafah), hubungan internasional (siyar), dan peradilan (murafa'at).

\subsection{Data Akhlak}

1. Tuturan:

"Bismillahirrahmanirrahim

Allahumma salli ala muhammad

Allahumma salli ala sayidina muhammad

Allahumma salli ala sayidina muhammadin wa ala alisayidinaa Muhammad (W/MA/AQ/10/11/15)

Pada data di atas memiliki arti sebagai berikut: "Dengan menyebut nama allah yang maha pengasih lagi maha penyanyang, ya tuhan kami, syalawatkanlah ke atas nabi Muhammad ya tuhan kami, syalawatkanlah ke atas pemimpin kami nabi Muhammad, 
LINGUA, Vol. 15, No. 2, September 2018

p ISSN: 1979 9411; e ISSN: 2442 238X

Http://lingua.pusatbahasa.or.id; Email:presslingua@gmail.com

Center of Language and Culture Studies, Surakarta, Indonesia

Irwansyah, Arifudin \& Yusran, Kamaludin. 2018. Nilai Nilai Mantra Bercocok Tanam di Desa Campa Kecamatan Madapangga Kabupaten Bima.

Lingua (2018), 15(2):175 186. DOI: 10.30957/lingua.v15i2.492.

ya tuhan kami, syalawatkanlah ke atas pemimpin kami nabi muhammad dan keatas keluarganya. Mantra ini mengandung nilai akhlak karena masyarakat memiliki jiwa persadaraan yang tinggi dengan sesama ummat termasuk keluarga-keluarga nabi Muhammad SAW.

\section{Tuturan:}

"...bismillahirrahmanirrahiim

Rumae mada doho di adamu manemba ndai ita ta ruma di ade babukai kanggihi lamada dohoke mbei japu mori ra woko di ruuba kanggihi lamada doho loa kaira wara di ngaha ra mori ra woko kai mada doho loakara tenggo sambea ra nemba di ndai ita ta rumae..." (W/HMHI/AK/13/11/15)

Pada data di atas memiliki arti sebagai berikut; "ya Allah kami sebagai hambamu menyembah engkau di saat kami memulai penanaman. Hidupkanlah dan perilaharalah tanaman kami supaya kami memiliki bekal untuk hidup. Sehingga kami kuat untuk selalu beribadah kepadamu". Mantra tersebut mengandung nilai akhlak karena memuat unsur hubungan manusia dengan mahluk ciptaan Allah lainya.

3. Tuturan:

"...bismillahirrahmanirrahiim

Ake madama babu kanggihi rumae, mbeijabu rejeki di ruuma mada adamu di ade kanggihi ra ngguda ra congge mada ake rumae, di loakai mori mada doho la adamu, di loakai beribadah ta ita rumae, nawarakura harta lamada di beribadah kai ta ita di sadeka kai lamada rumae loa kaira mada ndadi ada ma toa tai rumae barekala illaha illallah bareka muhammadarrasulullah..."

(W/T/AK/21/11/15)

Selanjutnya pada data di atas memiliki arti sebagai berikut; "dengan menyebut nama Allah yang maha pengasih lagi maha penyayang. Ya Allah inilah hamba yang memulai menanam di sawah dan ladang kami, berilah rezeki buat hamba yang sebagai petani di sawah dan di ladang kami, sehingga kami sebagai hambamu tetap bertahan hidup, untuk terus beribadah dan menyembah engkau, sehingga kami memiliki harta untuk beribadah kepadamu, untuk bersedekah kepada sesama, sehingga kami tergolong hamba-hambamu yang taat. Berkatilah ya Allah".Mantra tersebut mengandung nilai akhlak karena masyarakat memiliki keinginan untuk memeliharan alam untuk menciptakan hubungan manusia dengan alam. Selanjutnya manusia juga memiliki keinginan untuk bersedekah dan menjalin hubungan sosial saling berbagi dan tolong menolong kepada sesama.

Akhlak berarti perangai, adat istiadat, tabi'at atau sistem perilaku yang dibuat. Akhlak menurut istilah adalah sikap seseorang yang dimanifestasikan ke dalam perbuatan dan tingkah laku. Aklak menurut istilah ialah sikap seorang yang dimanifestasikan ke dalam perkataan perbuatan dan tingkah laku (Nurlela, 1999:91).

Menurut Fuadi, dkk. (2008:113) akhlak merupakan komponen dasar Islam yang ketiga yang berisi ajaran tentang perilaku atau sopan santun, atau dengan kata lain 
LINGUA, Vol. 15, No. 2, September 2018

p ISSN: 1979 9411; e ISSN: 2442 238X

Http://lingua.pusatbahasa.or.id; Email:presslingua@gmail.com

Center of Language and Culture Studies, Surakarta, Indonesia

Irwansyah, Arifudin \& Yusran, Kamaludin. 2018. Nilai Nilai Mantra Bercocok Tanam

di Desa Campa Kecamatan Madapangga Kabupaten Bima.

Lingua (2018), 15(2):175 186. DOI: 10.30957/lingua.v15i2.492.

akhlak dapat disebut sebagai aspek ajaran Islam yang mengatur perilaku manusia. Kajian akhlak bertumpu pada tingkah laku manusia, atau tepatnya nilai dari tingkah lakunya, yang bisa bernilai baik (mulia) atau sebaliknya bernilai buruk (tercela). Yang dinilai di sini adalah tingkah laku manusia dalam berhubungan dengan Tuhan, yakni dalam melakukan ibadah, dalam berhubungan dengan sesamanya, yakni dalam bermuamalah atau dalam melakukan hubungan sosial antar manusia, dalam berhubungan dengan makhluk hidup yang lain seperti binatang dan tumbuhan, serta dalam berhubungan dengan lingkungan atau benda-benda mati yang juga merupakan makhluk Tuhan. Secara singkat hubungan akhlak ini terbagi menjadi dua, yaitu akhlak kepad Khaliq (Allah Sang Pencipta) dan akhlak kepada makhluq (ciptaan-Nya). Pendapat lain mengenai akhlak dikemukakan oleh Bambang (2008:5-6). Akhlak merupakan kemampuan yang kuat tentang sesuatu yang dilakukan berulang-ulang sehingga menjadi adat yang membudaya yang mengarahkan pada kebaikan dan keburukan.

Melihat hasil wawancara di atas dapat disimpulkan bahwa sikap percaya masyarakat secara totalitas terhadap kekuatan yang ada di luar diri manusia membuat manusia menyerahkan diri sepenuhnya terhadap kekuatan tuhan untuk mengatur kehidupanya. Sikap menyerahkan diri sepenuhnya ini kemudian membuat manusia untuk meminta dan memohon kepada tuhan agar mendapat perlindungan, berkah, serta rezeki dari tuhan. Proses memohon dan meminta ini kemudian dilakukan dengan membacakan doa-doa serta aktifitas penyembahan dalam bentuk lain dalam kehidupan sehari-hari termasuk dalam aktifitas pertanian. Dalam kajian disiplin ilmu bahasa dan sastra Indonesia aktifitas meminta dan memohon lewat doa-doa ini kemudian disebut sebagai mantra.

Dari tahapan-tahapan masa pertanian dan bercocok tanam yang dilakukan oleh masyarakat dalam hal ini yang peneliti teliti pada masyarakata desa Campa kemudian peneliti bermaksud untuk mengkaji adanya nilai-nilai religius yang dikandung dalam mantra-mantra lisan dalam aktifitas pertanian masyarakat desa Campa. Nilai-nilai religius kemudian peneliti bagi kedalam tiga unsur yakni aqidah, syariah dan ahlak.

\section{SIMPULAN}

Nilai-nilai mantra bercocok tanam padi pada masyarakat desa Campa mengandung tiga unsur nilai yakni aqidah, syariah dan ahlak. Tiga unsur nilai yang terkandung pada mantra bercocok tanam ini kemudian tercakup dalam aktifitas pertanian yang dimulai dari tahapan awal yakni tahapan pengolahan lahan, tahap menengah yakni tahapan perawatan, dan tahapan terakhir yakni tahap panen.

Nilai-nilai mantra bercocok tanam masyarakat desa Campa mulai dari tahap pengolahan lahan dan penanaman serta tahapan perawatan mengandung unsur nilai aqidah yang merupakan penyerahan diri secara totalitas masyarakat desa Campa terhadap kebenaran adanya tuhan Allah SWT sebagai sumber kebenaran mutlak yang mengatur segala aktifitas manusia termasuk saat bercocoktanam. Yang kedua adanya kepercayaan masyarakat Campa terhadapa kebenaran diturunkanya nabi Muhammad SAW sebagai utusan Allah di atas muka bumi sehingga dalam kepercayaan petani 
LINGUA, Vol. 15, No. 2, September 2018

p ISSN: 1979 9411; e ISSN: 2442 238X

Http://lingua.pusatbahasa.or.id; Email:presslingua@gmail.com

Center of Language and Culture Studies, Surakarta, Indonesia

Irwansyah, Arifudin \& Yusran, Kamaludin. 2018. Nilai Nilai Mantra Bercocok Tanam di Desa Campa Kecamatan Madapangga Kabupaten Bima.

Lingua (2018), 15(2):175 186. DOI: 10.30957/lingua.v15i2.492.

masyarakat desa Campa kecamatan Madapangga kabupaten Bima dalam memulai pengolahan lahan dan penanaman padi terlebih dahulu harus percaya dan mengingat Allah SWT. Nilai yang kedua adalah nilai syariah yakni adanya keinginan yang besar dari masyarakat desa Campa untuk melaksanakan hukum-hukum tuhan di atas muka bumi dalam hal ini penyucian diri manusia agar tidak syirik dengan mengucapkan kalimat syahadat. Yang terakhir ialah nilai ahlak yakni adanya keinginanyang besar dari manusia untuk memelihara lingkungan dalam berhubungan dengan alam dan memenuhi kebutuhanya dalam berhubungan dengan diri sendiri dan manusia lain.

Kepercayaan yang di anut dalam Islam yang kemudian disebut sebagai aqidah, syariah, dan ahlak, khususnya bagi masyarakat yang Campa menganut kepercayaan terhadap agama Islam dan tidak boleh bertentangan dengan sistem nilai yang diatur dalam Islam yang kemudian akan disebut syirik. Penelitian ini menjadi bahan kepustakaan untuk memperkaya khasanah keilmuan khususnya dibidang sastra daerah bima dan dompu sehingga penelitian-penelitian selanjutnya sangat diharapkan untuk terus mempelajari sastra daerah masyarakat umumnya dan dunia akademisi khususnya menjadi melek pengetahuan terhadap sastra daerah

\section{DAFTAR PUSTAKA}

Al-Atsari, Abdullah bin Abdil Hamid. 2005. Panduan Aqidah Lengkap. Bogor: Pustaka Ibnu Katsir

Arikunto, Suharsini. 2010.Prosedur Penelitian Suatu Pendekatan Praktik. Jakarta: Rineka Cipta.

Ancok, Djamaludin \& Nasbori, Fuad. 2005. Psikologi Islami. Yogyakarta: Pustaka Pelajar.

Danangdjaja, James. 2002. Folklor Indonesia. Jakarta: Grafiti

Delvayanti.Susi 2012.Analisis Mantra Pada Upacara Perkawinan Adat Masyarakat Melayu Di Desa Terbangiang Kecematan Banggar Petalangan: UIR.

Depdikdas.2005. Kamus Besar Bahasa Indonesia. Edisi Ketiga. Jakarta: Balai Pustaka.

Dwi Santi, Purma dkk. 2013. Nilai-Nilai Religius Dalam Syair Selawat Dulang Di Kelurahan Koto Pulai Kecamatan Kota Tangah Kota Padang. (Jurnal) Pendidikan Bahasa dan Sastra Indonesia, Vol. 1 No. 2 Maret 2013; Seri F 399-476

Endraswara, Suwardi. 2013. Folklor Nusantara: Hakikat, Bentuk, dan Fungsi. Yogyakarta: Ombak

Endraswara, Suwardi. 2009. Metodologi Penelitian Folklor. Konsep, Teori, dan Aplikasi. Yogyakarta: Media Puastaka

Effendi dan Sabhan. 2007. Sastra Daerah. Banjarmasin: PBS FKIP Unifersitas Lambung Mangkurat

Farys, Zean (online). (http://zeanfarys.blogspot.co.id/2012/11/pengertian-dan-macammacan-mantra.html). Pengertian Dan Macam-Macan Mantra. Di akses sabtu 23 Januari 2016.

Fathoni, Miftah Ahmad. 2001. Pengantar Study Islam. Semarang: Percetakan Gunung Jadi. 
LINGUA, Vol. 15, No. 2, September 2018

p ISSN: 1979 9411; e ISSN: 2442 238X

Http://lingua.pusatbahasa.or.id; Email:presslingua@gmail.com

Center of Language and Culture Studies, Surakarta, Indonesia

Irwansyah, Arifudin \& Yusran, Kamaludin. 2018. Nilai Nilai Mantra Bercocok Tanam

di Desa Campa Kecamatan Madapangga Kabupaten Bima.

Lingua (2018), 15(2):175 186. DOI: 10.30957/lingua.v15i2.492.

Fuadi, Anwar dkk. 2008. Pendidikan Agama Islam di Perguruan Tinggi Umum. Padang: UNP Press

Hutomo, Suripan Sadi. 1991. Mutiara yang Terlupakan. Surabaya: HISKI Komisariat Jatim.

Jalil, Abdul dan Rahman Elmustiun. 2001. Puisi Mantra. Pekanbaru: Unri Pres.

Moleong. J. Lexy. 2006. Metodologi Penelitian Kualitatif. Bandung: Remaja Rosdakarya.

Nurlela.1999. Pendidikan Agama Islam. Padang: Universitas Negeri Padang.

Nasrul H. S dkk.2010. Pendidikan Agama Islam. Padang: UNP Press.

Narbuka, Cholid dan Abu Ahmadi. 2002. Metodologi Penelitian. Jakarta: Bumi Aksara.

Pudentia, MPSS (Ed). (2008). Metodologi Kajian Sastra Lisan. Jakarta: Asosiasi Tradisi Lisan.

Riduwan, 2005.Belajar Mudah Penelitian Untuk Guru-Karyawan Dan Peneliti Pemula.Bandung: Alfabeta.

Rakem. 2008. Mantra Bercocok Tanam Padi Sawah di Desa Leuweunggede (Analisis Struktur, Konteks Penuturan, Proses Penciptaan, dan Fungsi). Bandung: Universitas Pendidikan Indonesia (Prodi Bahasa dan Sastra Indonesia FPBS UPI)

Siswantoro. 2010. Metode Penelitian Sastra. Yogyakarta: Pustaka Pelajar

Suyasa, M. 2004. Teori Sastra. Mataram: Universitas Muhammadiyah Mataram.

Sugiyono. 2008. Metode Penelitian Pendidikan Pendekatan Kuantitatif, Kualitatif dan $R \& D$. Bandung: Alfabeta.

Sugiyono. 2012. Metode Penelitian Pendidikan Pendekatan Kuantitatif, Kualitatif, $R \& D$. Bandung: Alfabeta.

Subagyo, Joko. 2004. Metodologi Penelitian Dalam Teori Dan Praktek. Jakarta: Rineka Cipta.

Sukmadinata, Nana Syaodi. 2008. Metode Penelitian Pendidikan. Bandung: Remaja Rosdakarya.

Suratiyah, K. 2006. Ilmu Usahatani. Jakarta : Penebar Swadaya.

Tranggalek,Ipul. 2013. Nilai Agama. (Online). (Error! Hyperlink reference not valid.).Diakses pada tanggal 22 Agustus 2015.

Yadnya, Ida Bagus Putra. 1984. "Folklor Esetorik Dan Eksentorik" (Jurnal) Widya Pustaka, Th II No 1 Agustus. Dempasar: FS Udayana 